\title{
Lower Limb Joint Replacement in Patients with Rheumatoid Arthritis
}

\author{
Perioperative management considerations for patients with $R A$ \\ who need a total hip, knee, or ankle replacement
}

Nicholas D. Clement*, Stephen J.Breusch**, and Leela C.Biant*

\section{Introduction}

Rheumatoid arthritis (RA) is a chronic systemic connective tissue disease, and it is the third most common indication for lower limb joint replacement in Northern Europe and North America. [1] The etiology of the disease remains unclear, but there are strong associations with human leukocyte antigens (DRB1). [2] The prognosis is poor, with $80 \%$ of patients being disabled 20 years from primary diagnosis. [3] The medical treatment of RA has improved during the last 25 years, which is reflected by a $40 \%$ decrease in the rate of hip and knee surgery since a peak that was observed in the mid 1990s. [4] Anemia, raised erythrocyte sedimentation rate, and a high disease activity score have all been identified as risk factors for the need for large joint arthroplasty. [5]

Seventeen percent of patients with RA undergo an orthopaedic intervention within 5 years of initial diagnosis. [5] More than one third of patients will need a major joint replacement, of which the majority will receive a total hip or knee replacement (THR, TKR). [4] This review article summarizes factors involved in the perioperative management of major lower limb arthroplasty surgery for patients with RA.

\section{Methods of Literature Search}

We searched the PubMed [6] electronic database for studies published in English between 1960 and 2011. Our defined search term was: "rheumatoid" "replacement" "arthroplasty" and "outcome." This identified 669 eligible articles. All abstracts were reviewed and those matching the inclusion criteria were included; full papers were retrieved.

The inclusion criteria were:

- Articles reporting preoperative management of patients with RA receiving an orthopaedic intervention

- Articles reporting the survivorship and/or functional outcome and/or complications of primary total hip/knee/ankle replacements in patients with RA

- Articles reporting the survivorship and/or functional outcome and/or complications of revision total hip/knee/ankle replacements in patients with RA

- Articles reporting the rehabilitation of patients with RA after total hip/knee/ankle replacements

- Due to the insufficiency of published literature regarding arthroplasty in the patients with RA, further literature searches were executed. This was only performed when there were insufficient data to draw a conclusion about the question being addressed - for example, the use of tumor necrosis factor alpha (TNF $\alpha$ ) drugs in patients with RA undergoing arthroplasty surgery.

Royal Infirmary of Edinburgh, Little France, United Kingdom

* University of Heidelberg, Heidelberg, Germany 
Table 1. Systemic Preoperative Assessment of the Rheumatoid Patient

\begin{tabular}{|l|l|l|}
\hline History & Examinations & Investigations \\
\hline Disease onset & Complete medical & Full blood count \\
\hline Pattern and sequence & Joint inflammation & Urea \& creatinine \\
\hline Presences and persistent joint swelling & Joint damage and range of motion & Electrolytes \\
\hline Pain (site, severity, duration) & Soft tissue integrity & Liver function tests \\
\hline Morning stiffness & Extra-articular features & Chest radiograph \\
\hline Functional limitations & Grip strength & Cervical spine radiograph \\
\hline Non-articular features & General health & Electrocardiogram \\
\hline Psychological features & Dental inspection & Urine dipstick +/- culture \\
\hline Systemic features & Neurological assessment & Pulmonary function tests \\
\hline Review of all systems & & Echocardiogram (limiting cardiac pathology) \\
\hline Drugs and allergies & & Airway assessment \\
\hline Prior anaesthetic and surgery & & \\
\hline
\end{tabular}

There is a single prospective randomized control trial: 388 patients undergoing elective surgery were randomized to either cease or continue with methotrexate. [13] A 2\% infection rate occurred in those who continued methotrexate, with a decreased complication rate and number of flares of their rheumatoid disease. Those who stopped the methotrex-

\section{Preoperative Assessment}

In the preoperative assessment, the history, examination, and investigations need to be comprehensive, as described in Table 1. [7]

Eighty percent of RA patients have cervical spine involvement. Thirty percent have instability of the cervical spine, half of whom are asymptomatic. [8,9] Subluxation of the atlanto-axial joint, due to the destruction of the transverse ligament by inflammatory pannus, is defined as a distance of $>3 \mathrm{~mm}$ between the anterior aspect of the atlas and dens on a plain lateral cervical spine radiograph. [7] Clinical symptoms of occipital headache, weakness of limbs, bladder and bowel dysfunction, and long track signs should alert the clinician to such pathology. Computed tomography (CT) may be helpful to assess the extent of subluxation. [10]

\section{Immunosuppressants}

Steroids are used as a therapeutic bridge to control symptoms until the disease-modifying anti-rheumatic drugs (DMARDs) take effect. If a patient has used long-term steroids, an increased dose should be given in times of stress to prevent an Addisionian crisis. Use of steroids in the perioperative period for general surgical procedures increases the infection rate and impedes wound healing. [11] There is, however, no published literature regarding the risk of steroid use in the perioperative period for arthroplasty surgery

Methotrexate is a commonly used DMARD and has been shown to improve symptoms and slow radiographic progression of joint destruction. [12] ate had a $15 \%$ infection rate. Hence, it would seem safe and beneficial for the patient to continue methotrexate perioperatively, and it may aid their postoperative recovery.

Newer targeted immunotherapy such as TNF $\alpha$ antagonists are more effective in disease control, with slowing of radiographic joint destruction. [14] The evidence as to whether these drugs should be continued or stopped during orthopaedic procedures is limited. One study of 31 patients undergoing foot and ankle surgery demonstrated no difference in the infection rate if patients continued with their TNF $\alpha$ prescription. [15] A larger retrospective study of 128 patients undergoing major orthopaedic surgery revealed an increased infection risk in those who remained on $\mathrm{TNF} \alpha$ antagonists (odds ratio 21.8), and an associated increased risk of deep vein thrombosis (odds ratio 2.8). [16]

\section{Surgical Sequence}

Wilkinson et al suggest addressing lower limb arthropathy before the upper limb. Their hypothesis is that prior fragile upper limb interventions may be damaged by mobilization on crutches after lower limb surgery. [7] The surgical sequence they recommended is forefoot, hip, knee, hindfoot, and then ankle, which they deemed the order of "reliability" of the procedures. Constructing a base on which to build would be logical; the "reliability" of different procedures is arguable and individual patient assessment may dictate a different protocol. Hindfoot fusion may necessitate plaster immobilization, and could be considered at an earlier stage. Restoration of the correct femoral alignment and length 
with a THR precedes the TKR to allow correct implant alignment and rotation. Significant joint stiffness and/or contracture at adjacent or bilateral joints may be optimally addressed by simultaneous arthroplasty. Preoperative long leg standing alignment radiographs and a CT scan for assessment of soft tissue integrity and bone loss can help plan surgery.

\section{Total Hip Replacement}

Technical challenges of performing THR in patients with RA are mainly due to bone loss, osteopenia, and protrusio acetabuli. These patients are not suitable for hip resurfacing because of the risk of secondary osteoporosis. [17]

Until recently, there was little evidence to support the use of cemented over uncemented THR. Chmell et al reviewed 39 patients with juvenile rheumatoid disease (66 hips) who received a cemented THR with a mean follow of 15.1 years. [18] They report a stem survival of $85 \%$ and a cup survival of $70 \%$ for various implant designs. Creighton et al reviewed 75 patients (106 hips), all of whom received a cemented prosthesis. Stem survival was $98 \%$ and cup survival was $92 \%$ at 10 years. [19] They also demonstrated an association of cup loosening with younger patients. Jana et al, using an uncemented stem in 64 patients (82 hips) for juvenile RA, reported a survival of $98.1 \%$ at 11 years. However, various cemented and uncemented cups were used.

Analysis of 2,557 primary THRs using various implants for patients with RA from the Finnish arthroplasty register found the best survival to be with uncemented proximally circumferentially porouscoated stems ( $89 \%$ survival at 15 years) and cemented all-polyethylene cups ( $80 \%$ survival at 15 years). [20] However, more recent data from the Norwegian arthroplasty register suggested that cemented THR was superior to uncemented THR, with a 10 year survival of $89 \%$ and $81 \%$ respectively. [21]

Protrusio acetabuli is a common occurrence in the rheumatoid hip, and technical difficulties can be encountered due to medial wall deficiency. Two grading systems are used: that of Charnley, [22] relative to the ilio-pectineal line, and more commonly, Hirst et al, [23] relative to the ilio-ischial line (Table 2).
Table 2. Grading of Protrusio Acetabuli

Grading of protrusio acetabuli according to the distance between the acetabular line (medial wall of acetabulum) and the ilio-ischial line

\begin{tabular}{|l|l|l|}
\hline Grade & Men & Women \\
\hline I & $3-8 \mathrm{~mm}$ & $6-11 \mathrm{~mm}$ \\
\hline II & $8-13 \mathrm{~mm}$ & $12-17 \mathrm{~mm}$ \\
\hline III & $>13 \mathrm{~mm}$ with fragmentation & $>17 \mathrm{~mm}$ with fragmentation \\
\hline
\end{tabular}

Figure 1. Grade II protrusio acetabuli (A) in a female who underwent total hip replacement with medial bone graft and restoration of the center of rotation $(B)$.
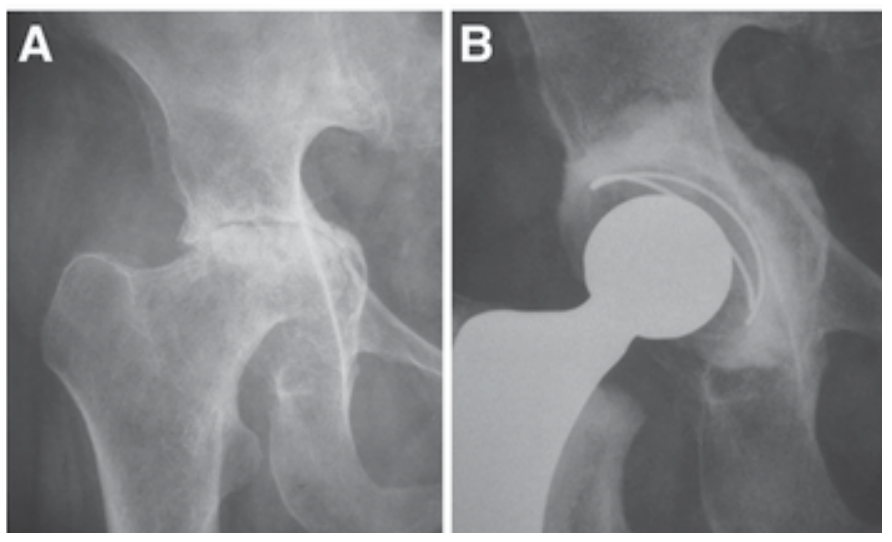

Figure 2. Grade III protrusio acetabuli $(A)$ with cage augmentation and medial bone graft $(B)$.
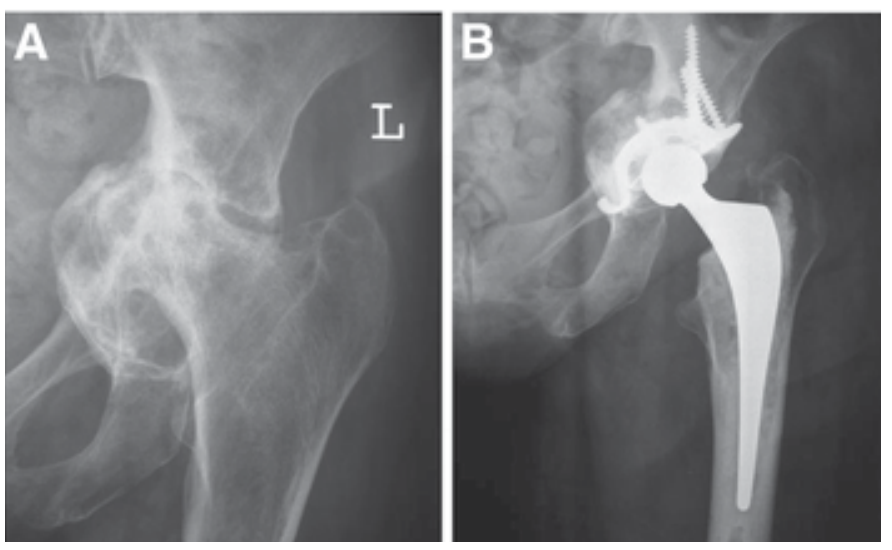

Hirst also described the Wrightington technique for bone grafting the acetabular floor, using 2-mm discs cut from the dislocated femoral head, which are molded using a dome pusher to conform to the acetabular floor. Restoration of the center of rotation lateral to Köhler's teardrop is essential (Figure 1). To further improve cement fixation, 6-mm holes may be drilled around the periphery of the acetabulum. The cement is placed directly onto the floor graft with insertion of the cup. More extensive acetabular destruction in Grade III protrusio may require a cage and additional bone grafting to prevent early failure (Figure 2). 
Figure 3. Valgus deformity of knee (A) due to avascular necrosis and bone destruction (B).

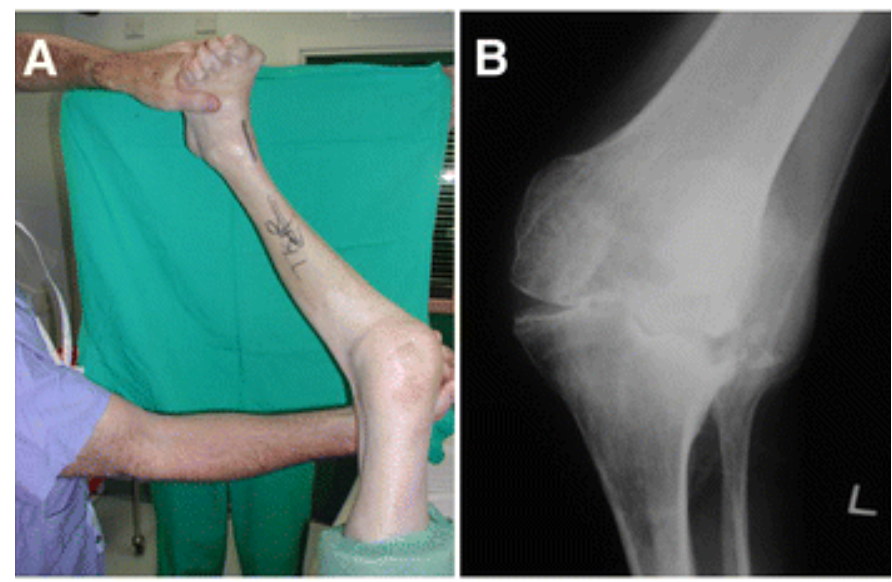

\section{Total Knee Replacement}

Poor bone stock, avascular necrosis, deformity, and contracture (Figure 3 ) can present technical challenges. Implant augmentation and bone grafting may be required. An implant that retains the posterior cruciate ligament (PCL) is favored by many surgeons for osteoarthritis of the knee. In rheumatoid disease, however, there is soft tissue destruction resulting in joint instability. Even if the PCL is intact intraoperatively, it may subsequently be eroded by inflammatory pannus postoperatively, resulting in an unstable prosthetic joint. Laskin reviewed 178 rheumatoid patients at an average of 8.2 years of follow up and demonstrated a 50\% instability rate with PCL-retaining implants, in contrast to a $1 \%$ instability rate with the PCL-sacrificing implants. [24]

Longer-term results in rheumatoid disease are limited. Goldberg et al [25] and Kristensen et al [26] demonstrated a $0 \%$ to $14 \%$ instability rate for PCLsacrificing implants, respectively. Gill et al [27] and Meding et al [28] have shown similar rates of insta-

Figure 4. Significant valgus deformity and concomitant medial collateral attenuation $(A)$ managed with a rotating hinge TKR $(B)$.
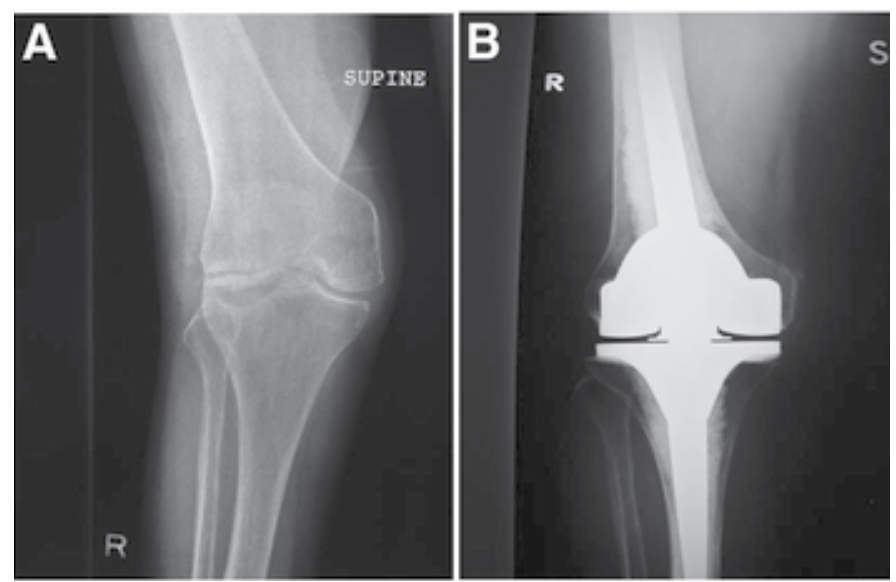

bility for PCL-retaining implants $(1.5 \%$ and $9.9 \%$, respectively). The differences between the reported instability rates may relate to disease severity and medical treatment, with more recent studies having the advantage of modern pharmacokinetics and preservation of soft tissues.

For patients with significant valgus deformity and concomitant medial collateral attenuation, a rotating hinge (Figure 4) may be the treatment of choice, [29] as an extensive lateral release may result in "overstuffing" of the joint, with an increased risk of midflexion instability. Furthermore, if the patient has a marked fixed flexion contracture of $>30$ degrees, then threshold for a constrained design should be low, particularly in older patients. [30]

The 15-year survival, excluding infection, for cemented total knee arthroplasty in patients with RA is $96.5 \%$ and $91 \%$ for PCL-retaining and PCL-sacrificing implants, respectively. [28,31] However, it could be argued that the increased failure rate in those who received a PCL-sacrificing implant had a higher grade of rheumatoid disease with severe joint destruction and, hence, the indication of a stabilized implant. Cemented implants may be the preferred option in poor bone stock and osteoporosis. Vigano et al described a 10-year survival rate of $98.4 \%$ using an uncemented TKR for RA patients. The average age of their cohort was 49.5 years. It could be argued that these patients had a better bone stock than older patients, facilitating osteointegration.

Shoji et al conducted a retrospective comparison of rheumatoid patients undergoing TKR with and without patella resurfacing, and they found no difference in pain or functional outcome. [32] In contrast, Kajino et al conducted a prospective randomized controlled trial of rheumatoid patients undergoing TKR, and they found improved pain relief and functional outcomes for patients receiving patella resurfacing. [33]

\section{Total Ankle Replacement}

The survival of total ankle replacement (TAR) does not parallel that of THR and TKR. The reported success rate of TAR in RA ranges from $40 \%$ to $100 \%$. [34] Mechanical loosening of the components is the major cause of revision surgery. [35] A recent long-term follow up of 33 TARs for RA reported an $85 \%$ survival rate at 10 years when failure was defined as removal of the prosthesis. The survival rate 
decreased to $64 \%$ if signs of radiographic loosening were included. [35]

Failure after TAR has been shown to be much higher in patients with greater than $15^{\circ}$ of varus or valgus deformity. [36,37] When a concomitant planovalgus forefoot abductus deformity exists, arthroplasty is a more difficult and less predictable procedure. Success will require a simultaneous or two-stage triple arthrodesis to correct the deformity, which is generally too severe to be corrected with a simple subtalar fusion. Patients are often frail or have poor soft tissues, making two-stage operations unattractive and a simultaneous triple arthrodesis a high-risk venture.

\section{Revision Arthroplasty Surgery}

Data regarding revision THR in rheumatoid patients are limited. The outcome of cemented cup revision for RA is inferior to patients without RA, with a $64 \%$ radiographic failure rate at 7 years. [38] This survival rate falls further at 9 years to $44 \%$ when an uncemented cup is used at revision. [39] Schreurs et al improved survival with the application of morselised bone graft in combination with a cemented cup at revision, reporting an $80 \%$ survival at 12 years. [40]

High failure rates have been reported for revision TKR in patients with RA. Garcia et al report a survival for all knees (27 mechanical failures and 18 infected revisions) of $76 \%$ at 5 years. They also, more worryingly, report a $34 \%$ mortality rate at 6 months for RA patients revised for infection. [41]

\section{Rehabilitation}

Patients with RA have a longer length of hospital stay, with slower functional improvement, than patients undergoing joint replacement surgery for primary osteoarthritis. A study of 1,361 rheumatoid patients and 26,096 osteoarthritic patients undergoing lower limb arthroplasty found the length of stay to be only 1 day longer, but it did show a slower, more gradual improvement of their functional independence score. [42] Stanley et al demonstrated that RA patients undergoing bilateral TKR had a similar functional outcome and complication rate as those undergoing staged procedures, but they had the benefit of a more rapid recovery relative to staged procedures. [43]

\section{Complications}

Evidence from the Swedish joint registry suggests that periprosthetic fractures are more common among patients with rheumatoid disease compared to osteoarthritis patients, with a hazard ratio (HR) of 1.56. [44] Similar figures have been reported from the Finnish registry (HR 2.1). [45] This predisposition to fracture may to be secondary to poor bone quality. [45] The management of periprosthetic fractures can be challenging and associated with high morbidity and mortality. [43]

The risk of arthroplasty infection is greater for patients with RA. Bongartz et al conducted a retrospective review of 462 patients (657 implants) who received either a TKR or THR. They compared infection rates for RA patients with a matched cohort of patients with osteoarthritis. [46] They found RA patients to be at an increased risk of prosthetic joint infections for both primary (HR 4.08, 95\% CI 1.3512.33 ) and revision surgery (HR 2.99, 95\% 1.028.75).

Conflicting evidence exists regarding the risk of venous thromboembolism (VTE) post-arthroplasty surgery in patients with RA, with Chotanaphuti et al. [47] declaring RA to be a risk factor and Guan et al [48] claiming RA to be protective for VTE. A retrospective review of nearly 5 million patients with RA showed that RA was an independent risk factor for pulmonary embolism and deep vein thrombosis in hospital patients who did not undergo surgery, with a relative risk of 2.25 and 1.9 , respectively. [49]

\section{Patient Outcomes}

Patients with active disease, raised rheumatoid titer, or clinical depression do not improve to the same extent as patients without. [50] Ethgen et al performed a cost/outcome analysis of arthroplasty for patients with RA, finding good pain relief that was equal to that of patients with primary osteoarthritis, but there was only a minor improvement in the functional outcome. [51] They also demonstrated reduced use of DMARDS, with cost savings, which may relieve the patient of drug-related adverse effects. Sledge proposed the key to a successful surgical outcome for patients with RA is for the surgeon to be familiar with the technical challenges of patients with polyarthritis and to work as part of a multidisciplinary team. [1] 


\section{Summary}

RA is a systemic disease, and as with any other medical co-morbidity, the patient should be optimized preoperatively using a multidisciplinary approach. The continued use of methotrexate does not increase infection risk, and aids an early recovery with control of the disease during the perioperative period. Biologic agents (TNF $\alpha$ antagonists) should be stopped preoperatively due to the increased infection rate. Patients should be made aware preoperatively of the increased risk of infection and periprosthetic fracture rates associated with their disease.

The surgical sequence is commonly hip, knee, and then ankle. Cemented THR and TKR have superior survival rates over uncemented components in RA patients. The need for bone grafting for protrusio acetabuli should be identified during preoperative planning. The evidence is not clear regarding a PCL-sacrificing versus a PCL-retaining implant in TKR, but a PCL-sacrificing component limits the risk of early instability and potential revision. Patella resurfacing as part of a TKR is associated with improved outcomes and should be considered in the rheumatoid patient. The results of TAR remain inferior to THR and TKR. RA patients achieve equivalent pain relief, but their rehabilitation is slower and their functional outcome is not as good. However, the key to managing these complicated patients is to work as part of a multidisciplinary team to optimize their outcome.

\section{Competing interests}

The authors declare that they have no competing interests.

\section{Author Information}

Nicholas D. Clement is an orthopaedic research fellow at the Royal Infirmary of Edinburgh, Little France, UK. Stephen J. Breusch is an orthopaedic surgeon at the University of Heidelberg, Heidelberg, Germany. Leela C. Biant is an orthopaedic surgeon at the Royal Infirmary of Edinburgh, Little France, UK.

\section{Source}

Clement ND, Breusch SJ, Biant LC. Lower limb joint replacement in rheumatoid arthritis. (C) 2012 Clement et al.; licensee BioMed Central Ltd. Jour- nal of Orthopaedic Surgery and Research 2012, 7:27 doi:10.1186/1749-799X-7-27. http://www.josr-online.com/content/7/1/27 Accessed 12/13/12. This is an Open Access article distributed under the terms of the Creative Commons Attribution License (http:// creativecommons.org/licenses/by/2.0), which permits unrestricted use, distribution, and reproduction in any medium, provided the original work is properly cited.

\section{References}

1. Sledge CB: Introduction to surgical management of patients with arthritis. In Kelly's Textbook of rheumatology. Edited by Saunders WB. Philadelphia; 2001. PubMed Abstract

2. Macgregor AJ, Snieder H, Rigby AS, Koskenvuo M, Kaprio J, Aho K, Silman AJ: Characterizing the quantitative genetic contribution to rheumatoid arthritis using data from twins. Arthritis Rheum 2000, 43:30-37.

3. Scott DL, Symmons DP, Coulton BL, Popert AJ: Long-term outcome of treating rheumatoid arthritis: results after 20 years. Lancet 1987, 1:11081111 .

4. Louie GH, Ward MM: Changes in the rates of joint surgery among patients with Rheumatoid Arthritis in California, 1983-2007. Ann Rheum Dis 2010, 69(5):868-871.

5. James D, Young A, Kulinskaya E, Knight E, Thompson W, Ollier W, Dixey J: Orthopaedic intervention in early rheumatoid arthritis. Occurrence and predictive factors in an inception cohort of 1064 patients followed for 5 years. Rheumatology (Oxford) 2004, 43:369-376.

6. http://www.ncbi.nlm.nih.gov/sites/entrez, http://www.ncbi.nlm.nih.gov/ sites/entrez

7. Wilkinson JM, Stanley D, Getty CJM: Surgical management of the rheumatoid patient. Curr Orthop 2004, 18:357-370.

8. Conlon PW, Isdale IC, Rose BS: Rheumatoid arthritis of the cervical spine. An analysis of 333 cases. Ann Rheum Dis 1966, 25:120-126.

9. Roche CJ, Eyes BE, Whitehouse GH: The rheumatoid cervical spine: signs of instability on plain cervical radiographs. Clin Radiol 2002, 57:241-249.

10. Takatori R, Tokunaga D, Hase H, Mikami Y, Ikeda T, Harada T, Imai K, Nishimura T, An HS, Inoue N, Kudo T: Three-dimensional morphology and kinematics of the craniovertebral junction in rheumatoid arthritis. Spine 2010, 35:1278-1284.

11. Anstead GM: Steroids, retinoids, and wound healing. Adv Wound Care 1998, 11:277-285.

12. Weinblatt ME, Maier AL, Fraser PA, Coblyn JS: Longterm prospective study of methotrexate in rheumatoid arthritis: conclusion after 132 months of therapy. J Rheumatol 1998, 25:238-242.

13. Grennan DM, Gray J, Loudon J, Fear S: Methotrexate and early postoperative complications in patients with rheumatoid arthritis undergoing elective orthopaedic surgery. Ann Rheum Dis 2001, 60:214-217.

14. Chen YF, Jobanputra P, Barton P, Jowett S, Bryan S, Clark W, Fry-Smith A, Burls A: A systematic review of the effectiveness of adalimumab, etanercept and infliximab for the treatment of rheumatoid arthritis in adults and an economic evaluation of their cost-effectiveness. Health Technol Assess 2006, 10(iii-xiii):1.

15. Bibbo C, Goldberg JW: Infectious and healing complications after elective orthopaedic foot and ankle surgery during tumor necrosis factor-alpha inhibition therapy. Foot Ankle Int 2004, 25:331-335. 
16. Kawakami K, Ikari K, Kawamura K, Tsukahara S, Iwamoto T, Yano K, Sakuma Y, Tokita A, Momohara S: Complications and features after joint surgery in rheumatoid arthritis patients treated with tumour necrosis factor-alpha blockers: perioperative interruption of tumour necrosis factor alpha blockers decreases complications? Rheumatology (Oxford) 2010, 49(2):341-347

17. Guidance on the use of metal on metal hip resurfacing arthroplasty. London: National Institute for Clinical Excellence; 2002. http://www.nice.org. uk/nicemedia/pdf/HipResurfacing-FinalGuidance.pdf.

18. Chmell MJ, Scott RD, Thomas WH, Sledge CB: Total hip arthroplasty with cement for juvenile rheumatoid arthritis. Results at a minimum of ten years in patients less than thirty years old. J Bone Joint Surg Am 1997, 79:44-52.

19. Creighton MG, Callaghan JJ, Olejniczak JP, Johnston RC: Total hip arthroplasty with cement in patients who have rheumatoid arthritis. A minimum ten-year follow-up study. J Bone Joint Surg Am 1998, 80:14391446 .

20. Eskelinen A, Paavolainen P, Helenius I, Pulkkinen P, Remes V: Total hip arthroplasty for rheumatoid arthritis in younger patients: 2,557 replacements in the Finnish Arthroplasty Register followed for 0-24 years. Acta Orthop 2006, 77:853-865.

21. Havelin LI, Hallan G, Dybvik E: Cemented verses uncemented femoral stems in rheumatoid arthritis patients in th Norwegian arthroplasty register. European Federation of National Associations Of Orthopaedics and Traumatology (8th Congress) 2007, Vol. Florence(91-B ed):89-90.

22. Sotelo-Garza A, Charnley J: The results of Charnley arthroplasty of hip performed for protrusio acetabuli. Clin Orthop Relat Res 1978, 12:8.

23. Hirst P, Esser M, Murphy JC, Hardinge K: Bone grafting for protrusio acetabuli during total hip replacement. A review of the Wrightington method in 61 hips. J Bone Joint Surg Br 1987, 69:229-233.

24. Laskin RS, O'Flynn HM: The Insall Award. Total knee replacement with posterior cruciate ligament retention in rheumatoid arthritis. Problems and complications. Clin Orthop Relat Res 1997, 24:8.

25. Goldberg VM, Figgie MP, Figgie HE, Heiple KG, Sobel M: Use of a total condylar knee prosthesis for treatment of osteoarthritis and rheumatoid arthritis. Long-term results. J Bone Joint Surg Am 1988, 70:802-811.

26. Kristensen O, Nafei A, Kjaersgaard-Andersen P, Hvid I, Jensen J: Longterm results of total condylar knee arthroplasty in rheumatoid arthritis. J Bone Joint Surg Br 1992, 74:803-806.

27. Gill GS, Joshi AB: Long-term results of retention of the posterior cruciate ligament in total knee replacement in rheumatoid arthritis. J Bone Joint Surg Br 2001, 83:510-512.

28. Meding JB, Keating EM, Ritter MA, Faris PM, Berend ME: Long-term followup of posterior-cruciate-retaining TKR in patients with rheumatoid arthritis. Clin Orthop Relat Res 2004, 146:52.

29. Morgan H, Battista V, Leopold SS: Constraint in primary total knee arthroplasty. J Am Acad Orthop Surg 2005, 13:515-524

30. Sculco TP: The role of constraint in total knee arthroplasty. J Arthroplasty 2006, 21:54-56.

31. Rodriguez JA, Saddler S, Edelman S, Ranawat CS: Long-term results of total knee arthroplasty in class 3 and 4 rheumatoid arthritis. J Arthroplasty 1996, 11:141-145.

32. Shoji H, Yoshino S, Kajino A: Patellar replacement in bilateral total knee arthroplasty. A study of patients who had rheumatoid arthritis and no gross deformity of the patella. J Bone Joint Surg Am 1989, 71:853-856.

33. Kajino A, Yoshino S, Kameyama S, Kohda M, Nagashima S: Comparison of the results of bilateral total knee arthroplasty with and without patellar replacement for rheumatoid arthritis. A follow-up note. J Bone Joint Surg Am 1997, 79:570-574
34. Michael JM, Golshani A, Gargac S, Goswami T: Biomechanics of the ankle joint and clinical outcomes of total ankle replacement. J Mech Behav Biomed Mater 2008, 1:276-294.

35. Jensen NC, Linde F: Long-term follow-up on 33 TPR ankle joint replacements in 26 patients with rheumatoid arthritis. Foot Ankle Surg 2009, $15: 123-126$.

36. Hobson SA, Karantana A, Dhar S: Total ankle replacement in patients with significant pre-operative deformity of the hindfoot. J Bone Joint Surg Br 2009, 91:481-486.

37. Wood PL, Crawford LA, Suneja R, Kenyon A: Total ankle replacement for rheumatoid ankle arthritis. Foot Ankle Clin 2007, 12:497-508.

38. Raut VV, Siney PD, Wroblewski BM: Cemented revision Charnley lowfriction arthroplasty in patients with rheumatoid arthritis. J Bone Joint Surg Br 1994, 76:909-911.

39. Mont MA, Domb B, Rajadhyaksha AD, Padden DA, Jones LC, Hungerford DS: The fate of revised uncemented acetabular components in patients with rheumatoid arthritis. Clin Orthop Relat Res 2002, 140:8.

40. Schreurs BW, Thien TM, de Waal Malefijt MC, Buma P, Veth RP, Slooff TJ: Acetabular revision with impacted morselized cancellous bone graft and a cemented cup in patients with rheumatoid arthritis: three to fourteen-year follow-up. J Bone Joint Surg Am 2003, 85-A:647-652.

41. Garcia RM, Hardy BT, Kraay MJ, Goldberg VM: Revision total knee arthroplasty for aseptic and septic causes in patients with rheumatoid arthritis. Clin Orthop Relat Res 2010, 468:82-89.

42. Nguyen-Oghalai TU, Ottenbacher KJ, Caban M, Granger CV, Grecula M, Goodwin JS: The impact of rheumatoid arthritis on rehabilitation outcomes after lower extremity arthroplasty. J Clin Rheumatol 2007, 13:247250 .

43. Stanley D, Stockley I, Getty CJ: Simultaneous or staged bilateral total knee replacements in rheumatoid arthritis. A prospective study. J Bone Joint Surg Br 1990, 72:772-774.

44. Lindahl H, Malchau H, Oden A, Garellick G: Risk factors for failure after treatment of a periprosthetic fracture of the femur. J Bone Joint Surg Br 2006, 88:26-30.

45. Sarvilinna R, Huhtala HS, Puolakka TJ, Nevalainen JK, Pajamaki KJ Periprosthetic fractures in total hip arthroplasty: an epidemiologic study. Int Orthop 2003, 27:359-361.

46. Bongartz T, Halligan CS, Osmon DR, Reinalda MS, Bamlet WR, Crowson CS, Hanssen AD, Matteson EL: Incidence and risk factors of prosthetic joint infection after total hip or knee replacement in patients with rheumatoid arthritis. Arthritis Rheum 2008, 59:1713-1720.

47. Chotanaphuti T, Ongnamthip P, Songpatanasil T, Veerapan P, Deeprecha $\mathrm{K}$ : Risk factors of deep vein thrombosis (DVT) after total knee arthroplasty (TKA) at Phramongkutklao Hospital. J Med Assoc Thai 2007, 90:485491.

48. Guan ZP, Lu HS, Chen YZ, Song YN, Qin XL, Jiang J: Clinical risk factors for deep vein thrombosis after total hip and knee arthroplasty. Zhonghua Wai Ke Za Zhi 2005, 43:1317-1320.

49. Matta F, Singala R, Yaekoub AY, Najjar R, Stein PD: Risk of venous thromboembolism with rheumatoid arthritis. Thromb Haemost 2009, 101:134-138.

50. Benjamin A, Helal B: Surgical repair and reconstruction in rheumatoid disease. London: The Macmillan Press; 1980

51. Ethgen O, Kahler KH, Kong SX, Reginster JY, Wolfe F: The effect of health related quality of life on reported use of health care resources in patients with osteoarthritis and rheumatoid arthritis: a longitudinal analysis. J Rheumatol 2002, 29:1147-1155. 